\title{
Applying Revenue Management to Economy Hotels--- An Investigation of Customer's Attitude
}

\author{
Wen-li Li
}

\begin{abstract}
Department of Hotel, Shenzhen Tourism College, Jinan University, Shenzhen City, Guangdong Province, China
\end{abstract}
\begin{abstract}
Revenue management is an effective strategy for the economy hotels to increase profit. However, implementing revenue management may also bring misunderstanding and negative feelings to the customers. This study investigates the customers' attitude to the revenue strategies of economy hotels. Based on data analysis, the following conclusions have been made: the customers of economy hotels feel positive about differential pricing, however, they feel negative about capacity control and overbooking. Besides, there are significant differences about the customers' attitude to the three revenue strategies in terms of the customers' age, career, education, annual income and tourism objective apart from gender. Finally, this paper proposes some suggestions to the economy hotel managers to implement revenue strategy accordingly.
\end{abstract}

Keywords — economy hotel, revenue management, customer attitude

\section{经济型酒店应用收益管理策略的研究一一基于顾客态 度的调查}

\author{
李文丽 \\ 暨南大学深圳旅游学院酒店管理系, 深圳, 广东, 中国
}

摘 要 收益管理是目前酒店用来增加收益的有效策略, 但是收益管理的实施容易引起顾客的误解及负面感受。本研究以经济型酒 店为例, 针对顾客对收益管理策略实施的态度进行调查。通过数据统计与分析, 得出以下结论: 经济型酒店顾客对收益管理的差异定 价策略的态度比较正面, 而对对客房分配与超量预订策略的态度比较消极。顾客中除了性别外, 年龄、职业、学历、年收入、入住目 的对收益管理策略的态度均存在不同程度的显著差异。最后, 研究根据调查结论为经济型酒店管理者提出了相应的改进策略。

关键词 经济型酒店, 收益管理策略, 顾客态度

\section{1. 引言}

近年来, 我国酒店业进入高速发展期, 以满足大众化 消费为目的的经济型酒店增长尤其迅速。随着这些经济型 连锁酒店的兴起，市场竞争越趋激烈。

经济型酒店收入来源比较单一, 以客房产品为核心。 而酒店的初始建设成本高, 边际运营维护成本低; 客房是 不可存咜的; 客房数量短时间内是固定的; 客房需求呈现 季节性变动这四大特性, 要求酒店必须采取收益管理相关 策略以增加酒店营业收入[1][2]。

然而, 在实施收益管理过程中, 常常出现酒店与顾客
之间的冲突与矛盾。比如有些顾客不认同酒店的差异定价 策略, 认为酒店对于同一类型产品面对不同顾客都应该收 取一样的价格。由于酒店实施收益管理所引起的顾客不满 对酒店的品牌形象与长期利益有一定的负面影响, 因此酒 店必须注重其顾客对于收益管理的态度。

酒店如何在长期收益与短期收益之间取得平衡, 并获 得整体收益最大化, 需要我们基于顾客感受探索经济型酒 店实施收益管理的影响并利制定有效的管理方针。

国家自然科学基金项目支持（资助号：11301223） 


\section{2. 相关概念}

在收益管理策略最开始被应用于美国航空业后, 国外 关于收益管理的研究发展迅速。Kimes（1989）等学者对收 益管理的适用性进行了研究, 认为收益管理策略适用于带 有以下特点的企业: (1)产品或服务带有时效性; (2)产品或 服务供应比较稳定; (3)产品或服务能够提前出售; (4)顾客 对产品或服务的需求层次能够清晰分类; (5)顾客对产品或 服务的需求具有波动性; (6)产品或服务具有不可存储性, 销售成本相对较低[1][3]。酒店管理已经被公认为一个非常 适合使用收益管理策略的行业。McGill 和 Ryzin (1999) 提 出了收益管理在适用行业中的实践策略主要包括了: 差异 定价、客房控制以及超额预订等等[4]。

\section{1 差异定价 (Differential Pricing)}

差异定价是收益管理中一种重要的控制方法, 关键在 于根据市场需求决定价格策略, 制定差异化的价格[5]。在 需求旺季尽力提高房价来增加收益以及在需求淡季尽力提 高入住率并使房价达到均衡。还包括对于不同房型在同一 时段的定价策略与同一房型面向不同群体的定价策略。

\section{2 客房分配 (Capacity Control)}

客房分配, 即合理地根据不同的客户群体或细分市场 分配现有客房资源。其目的在于尽量将合适的客房出售给 那些愿意支付更高房费的顾客, 以此来有效地提高酒店的 收益[6]。但当高房价客房预订超过上限时, 可牺牲部分低房 价客房的分配量来优先满足高价客房的需求。

\section{3 超量预订 (Overbooking)}

超量预订, 是指酒店接受比所有客房数更多的预订, 目的是为了预防顾客临时取消或者根本没有到达酒店, 造 成客房浪费。但在实践中超订面临一定的风险, 一旦预订 的顾客全部抵达酒店, 饭店将面临旧尤的局面。因而超量 预订幅度就十分关键, 要确定超订的最佳水平必须要权衡 超售带来的收益和可能的赔偿损失[7]。

\section{3. 研究方法}

\section{1 问卷设计}

调查问卷内容分为两部分, 第一部分是顾客对经济型 酒店实施收益管理策略的感受程度调查。根据研究模型中 的三个变量 (需求预测、客房分配与超量预订) 分别设置 衡量项目。因为顾客不一定都能够实际经历与感受过酒店 实施收益管理的每个策略, 例如超量预订导致顾客预订后
无法取得相应的客房。所以问卷的第一部分题目采用第一 人称的方式, 假设在发生相关情况下, 受访者的满意程度。 采用 Likert 的 5 级顺序量表, 文字表述为非常不同意、比 较不同意、一般、比较同意、非常同意, 相应分值为 $1 、 2 、$ 3、4、5。同时, 问卷第一部分还包括调查受访者关于酒店 提供补偿以及对经济型酒店品牌的选择偏好。

问卷的第二部分是受访者的个人资料, 目的是为了解 受访者的人口特征对各个变量接受程度的差异情况, 包括 受访者的性别、年龄、学历、职业、收入、旅游目的等。

\section{2 问卷调查}

本次调查面向有经济型酒店入住经验的消费者。问卷 发放全部通过网络途径发放电子版问卷, 研究选择问卷 星网站为调查平台, 邀请有相关经验的网友参与调查。 调查最终发放并顺利回收问卷 215 份, 其中有效样本为 196 份, 有效率约为 $91.2 \%$ 。

\section{4. 数据分析}

\section{1 人口信息统计}

本次调查共回收问卷 215 份, 为了增加数据的有效度, 通过篮选剔除了填表时间过快 (少于 40 秒的)、所有选项 答案一样的、总分过高或过低的以及 IP 地址重复的样本共 19 份, 得到有效样本 196 份。有效样本人口信息见表 4-1.

\section{2 描述性统计}

经济型酒店顾客分别对收益管理三大策略的态度总平 均值如表 4-2 所示。

如表 4-2 可知, 顾客对差异定价接受程度的总平均值为 三个策略中的最高值, 达到 3.59 , 说明顾客比较认同与接 受差异定价策略, 对差异定价的态度是正面的, 经济型酒 店管理者可以考虑多运用差异定价策略。相对的, 顾客对 客房分配与超量预订策略态度的总平均值分别为 2.97 、 3.00 , 态度较为消极, 因此管理者在运用时需要谨慎对待。

\section{3 方差分析}

为了解不同的受访者对于调查的研究变量的态度存在 着怎样的显著差异, 本研究运用单因素方差分析(ANOVA 分析) 研究人口信息对研究变量的影响。以下为调查中的人 口信息对研究变量的方差分析:

(1) 性别对研究变量的方差分析

根据表 4-3, 性别对三个研究变量的显著性均大于 0.05, 因此受访者的性别对于各研究变量没有显著影响。 
表 4-1 人口信息统计表

\begin{tabular}{|c|c|c|c|}
\hline \multicolumn{2}{|c|}{ 类别 } & 人数 & 百分比 \\
\hline \multirow{2}{*}{ 性别 } & 男 & 92 & $46.94 \%$ \\
\hline & 女 & 104 & $53.06 \%$ \\
\hline \multirow{5}{*}{ 年龄 } & 22 岁及以下 & 57 & $29.08 \%$ \\
\hline & 23-30 岁 & 100 & $51.02 \%$ \\
\hline & 31-40 岁 & 25 & $12.76 \%$ \\
\hline & 40-50 岁 & 13 & $6.63 \%$ \\
\hline & 50 岁以上 & 1 & $0.51 \%$ \\
\hline \multirow{5}{*}{ 职业 } & 学生 & 88 & $44.9 \%$ \\
\hline & 事业单位人员 & 23 & $11.73 \%$ \\
\hline & 国内企业人员 & 57 & $29.08 \%$ \\
\hline & 跨国企业人员 & 10 & $5.1 \%$ \\
\hline & 个体经营者 & 7 & $3.57 \%$ \\
\hline \multirow{4}{*}{ 学历 } & 高中及以下 & 8 & $4.08 \%$ \\
\hline & 大专 & 19 & $9.69 \%$ \\
\hline & 本科 & 151 & $77.04 \%$ \\
\hline & 硕士及以上 & 18 & $9.18 \%$ \\
\hline \multirow{5}{*}{ 年收入 } & 5 万元及以下 & 110 & $56.12 \%$ \\
\hline & 5-10 万元 & 48 & $24.49 \%$ \\
\hline & 10-20 万元 & 32 & $16.33 \%$ \\
\hline & 20-30 万元 & 4 & $2.04 \%$ \\
\hline & 30 万元以上 & 2 & $1.02 \%$ \\
\hline \multirow{4}{*}{ 入住目的 } & 商务出差 & 54 & $27.55 \%$ \\
\hline & 休闲度假 & 132 & $67.35 \%$ \\
\hline & 探亲访友 & 8 & $4.08 \%$ \\
\hline & 其它 & 2 & $1.02 \%$ \\
\hline 合计 & & 196 & $100 \%$ \\
\hline
\end{tabular}

表 4-2 三个策略的总平均值

\begin{tabular}{|c|c|}
\hline 收益管理策略 & 总平均值 \\
\hline 差异定价 & 3.59 \\
\hline 客房分配 & 2.97 \\
\hline 超量预订 & 3.00 \\
\hline
\end{tabular}

表 4-3 性别方差分析

\begin{tabular}{|c|c|c|}
\hline 研究变量 & F & 显著性 \\
\hline 差异定价 & 2.528 & 0.070 \\
\hline 客房分配 & 2.833 & 0.112 \\
\hline 超额预订 & 3.202 & 0.159 \\
\hline
\end{tabular}

表 4-4 年龄方差分析

\begin{tabular}{|c|c|c|}
\hline 研究变量 & F & 显著性 \\
\hline 差异定价 & 2.138 & 0.145 \\
\hline 客房分配 & 6.175 & 0.014 \\
\hline 超量预订 & 3.894 & 0.051 \\
\hline
\end{tabular}

表 4-5 学历方差分析

\begin{tabular}{|c|c|c|}
\hline 研究变量 & F & 显著性 \\
\hline 差异定价 & 1.051 & 0.389 \\
\hline 客房分配 & 3.070 & 0.011 \\
\hline 超额预订 & 3.932 & 0.002 \\
\hline
\end{tabular}

表 4-6 职业方差分析

\begin{tabular}{|c|c|c|}
\hline 研究变量 & F & 显著性 \\
\hline 差异定价 & 1.453 & 0.218 \\
\hline 客房分配 & 4.724 & 0.001 \\
\hline 超量预订 & 4.267 & 0.002 \\
\hline
\end{tabular}

表 4-7 年收入方差分析

\begin{tabular}{|c|c|c|}
\hline 研究变量 & F & 显著性 \\
\hline 差异定价 & 3.804 & 0.011 \\
\hline 客房分配 & 0.534 & 0.659 \\
\hline 超量预订 & 0.674 & 0.569 \\
\hline
\end{tabular}

表 4-8 入住目的方差分析

\begin{tabular}{|c|c|c|}
\hline 研究变量 & F & 显著性 \\
\hline 差异定价 & 2.547 & 0.057 \\
\hline 客房分配 & 10109 & 0.347 \\
\hline 超量预订 & 3.753 & 0.012 \\
\hline
\end{tabular}

表 4-9 人口信息对研究变量的显著差异

\begin{tabular}{|c|c|c|c|}
\hline 特征 & 差异定价 & 客房分配 & 超量预订 \\
\hline 性别 & $\times$ & $\times$ & $\times$ \\
\hline 年龄 & $\times$ & $\sqrt{ }$ & $\sqrt{ }$ \\
\hline 职业 & $\times$ & $\sqrt{ }$ & $\sqrt{ }$ \\
\hline 学历 & $\times$ & $\sqrt{ }$ & $\sqrt{ }$ \\
\hline 年收入 & $\sqrt{ }$ & $\times$ & $\times$ \\
\hline 入住目的 & $\times$ & $\times$ & $\sqrt{ }$ \\
\hline
\end{tabular}




\section{（2）年龄对研究变量的方差分析}

根据表 4-4, 年龄对差异定价与超量预订的显著性均大 于 0.05 , 年龄对客房分配显著性为 0.014 , 小于 0.05 , 因此 受访者的年龄对于客房分配有显著影响, 对其他研究变量 没有显著影响。

\section{（3）学历对研究变量的方差分析}

根据表 4-5, 学历对差异定价的显著性大于 0.05 , 为 0.389 , 因此受访者的学历对于差异定价没有显著影响。而 受访者的学历对客房分配与超量预订的显著性均小于 0.05 , 说明学历对于客房分配与超量预订有显著影响。

\section{（4）职业对研究变量的方差分析}

根据表 4-6, 职业对差异定价的显著性大于 0.05, 对客 房分配与超量预订显著性偏低, 小于 0.05 , 因此受访者的 职业对于差异定价没有显著影响, 对于客房分配与超量预 订有显著影响。

\section{（5）收入对研究变量的方差分析}

根据表 4-7, 年收入对除差异定价外的两个研究变量的 显著性均大于 0.05 , 因此受访者的年收入对于差异定价有 显著影响, 对其他研究变量没有显著影响。

\section{（6）入住目的对研究变量的方差分析}

据表 4-8, 入住目的对除超量预订外的研究变量的显著 性均大于 0.05 , 因此受访者的入住目的对于超量预订有显 著影响，对于差异定价和客房分配没有显著影响。

结合以上方差分析可得出以下分析结果，(如表 4-9), 性别对于差异定价、客房分配、超量预订三个变量无显著 差异; 年龄、职业与学历都对客房分配与超量预订有显著 差异，对差异定价都没有显著差异; 年收入对差异定价有 显著差异，对客房分配与超量预订没有显著差异；入住目 的只对超量预订有显著差异。

\section{5. 研究结论}

本研究得出以下结论, 经济型酒店顾客对于收益管理 策略中的差异定价策略的态度比较正面, 对于客房分配和 超量预订策略认同程度则不高, 管理者使用时需谨慎而为。 顾客中除了性别外，年龄、职业、学历、年收入、入住目 的对收益管理策略的态度均存在不同程度的显著差异。建 议经济型酒店的决策者, 在实施收益管理时采取如下策略:

第一，适度增加差异定价的使用频率。虽然顾客对差 异定价的总体态度比较正面, 可是如果顾客的年收入不同, 对差异定价行为的态度仍有显著区别。假若由于顾客不满 导致老顾客的流失，酒店吸引一个新顾客需要花费更多的
资源, 对酒店长期利益来说是得不偿失的。所以在进行差 异定价时决策者可以在提高房价的时候适当地提供一些额 外的服务以补偿消费者的不满意程度, 如延迟退房等。第 二、客房分配应该考虑顾客感受。客房分配题项得分较低 表明顾客对于客房分配行为接受程度不高，管理者在实施 客房分配时应该考虑顾客感受，而不是一味为了增加酒店 收益而忽略顾客感受。第三、超量预订应控制在合理水平。 超量预订不能过度, 过度的超量预订将为酒店带来顾客不 满甚至顾客投诉, 影响酒店形象, 损害酒店长期利益, 所 以管理者应该将超量预订控制在合理的水平。第四、通过 培训增强员工对收益管理的理解与沟通能力。酒店实施收 益管理不仅仅是管理层的事，还应该是全体员工关注的事。 只有透过培训让全体员工了解收益管理才能调动起酒店里 面的工作人员一起为酒店增收而努力，达到酒店经营目标。

总之，经济型酒店收益管理的决策者，要兼顾顾客感 受与酒店收益水平。既要关心酒店短期利益，更应该关注 酒店的长期发展。

\section{参考文献(References)}

[1] S. E. Kimes, "The basics of yield management", Cornell Hotel and Restaurant Administration Quarterly, vol. 30, pp. 14-19, 1989.

[2] S. E. Kimes, "Revenue Management on the Links", Cornell Hotel and Restaurant Administration Quarterly, vol 41, pp.120-127, 2001,

[3] W. Chiang, J. Chen, and X. Xu, "An overview of research on revenue management: current issues and future research", International Journal of Revenue Management, vol. 1, pp. 97-128, 2007

[4] J. Mcgill, and G. Ryzin. , "Revenue management : Research Overview and Prospects", Transportation Science, vol 3, no. 2, pp. 33-256, 1999.

[5] T. Kalyan, and G. Ryzin, "Revenue management under a general discrete choice model of consumer behavior", Management Science, vol. 50, no. 1, pp. 15-33, 2004.

[6] E. B. Orkin, "Boosting Your Bottom Line with Yield Management", Cornell Hotel and Restaurant Administration Quarterly, vol. 28, no. 4, pp. 52-56, 1988.

[7] R. D. Badinelli, "An optional, dynamic policy for hotel yield management", European Journal of Operational Research, vol. 121, pp. 476-503, 2000. 